desired few children, lived in urban areas and belonged to a non-traditional ethnic group, i.e. non-Bedouin. ${ }^{4}$

A higher level of fertility has been associated with 'traditional' religious prohibition on some form of birth control, traditional values about the importance of children and the priority of the family. The UAE is among those societies in which social and religious rules have favoured the abundant production of children. In our study, 121 (40.61\%) men have more than five children and among them $14(18 \%)$ never practised any form of contraception.

Responsibility of contraception falls mainly on women being the wife's responsibility. Despite a reasonable level of awareness overall, i.e. $84.5 \%$ and a positive attitude to contraception, only a small proportion of men $(27.0 \%)$ ever practised any male contraceptive methods. Economic factors were not found to be affecting contraceptive practice in lower and upper class populations in the study group, where nearly the same level of contraceptive use was found. However, a higher level of contraceptive use was noted in the middle-income population. This could be partly explained by the higher level of education and employment of the wives in this subgroup.

To our knowledge this is the first study of its kind in the UAE, and due to the rapid economic development and influence of the information revolution we anticipate that male contraceptive knowledge and use may change positively in the near future.
Statements on funding and competing interests

Funding. None identified.

Competing interests. None identified.

References

1 Huezo CM. Current reversible contraceptive methods: a global perspective. Int J Gynaecol Obstet 1998; 62(Suppl. 1): S3-S15.

2 Hair WM, Wu FC. Male contraception: prospects for the new millennium. Asian J Androl 2000; 2: 3-12.

3 Ringheim $\mathrm{K}$. Factors that determine prevalence of use of contraceptive methods for men. Stud Fam Plann 1993; 24: 87-99.

4 Shah NM, Shah MA, Al-Rahmani E. Contraceptive use among Kuwaitis, 1984-1999. Int J Gynaecol Obstet 2001; 73: 173-175.

5 Ozvaris SB, Dogan BG, Akin A. Male involvement in family planning in Turkey. World Health Forum 1998; 19: 76-78.

6 Chipfakacha VG. Attitudes of males on contraception: a KAPE survey. East Afr Med J 1993; 70: 82-84.

7 Cochran WG. Sampling techniques (3rd edn). New York, NY: John Wiley \& Sons, 1977; 72-88.

8 Sai FT. Political and economic factors influencing contraceptive uptake. Br Med Bull 1993; 49: 200-209

9 Brown GF, Moskowitz EH. Moral and policy issues in long-acting contraception. Annu Rev Public Health 1997; 18: 379-400.

10 Ghazal-Aswad S, Rizk DEE, Al-Khoori SM, et al. Knowledge and practice of contraception in United Arab Emirates women. J Fam Plann Reprod Health Care 2001; 27: 209-212.

11 Farley TM, Meirik O, Mehta S, et al. The safety of vasectomy: recent concerns. Bull World Health Organ 1993; 71(3-4): 413-419.

12 Parker RM, Williams MV, Baker DW, et al. Literacy and contraception: exploring the link. Obstet Gynecol 1996; 88 (3 Suppl.): 72S-77S

\begin{tabular}{llr}
\hline F & Faculty & A CPD Self-Assessment Test \\
A & Aid to & \\
C & CPD & ANSWER SHEET \\
T & Topics & ANWE \\
\hline
\end{tabular}

\title{
Bleeding problems and progestogen-only contraception
}

1. Progestogen induces proliferative change in the endometrium.

Answer

2. Under the influence of synthetic progestogens, endometrial bleeding comes from the spiral arterioles.

False

3. Circulating progestogen levels are linked to the bleeding pattern.

False

4. When abnormal bleeding patterns are produced by the POP there is evidence to suggest that changing

brands is helpful.

False

False

5. Bleeding problems with progestogen only methods improve with time.

True

6. Implanon ${ }^{\circledR}$ produces a higher rate of amenorrhoea than Depo-Provera ${ }^{\circledR}$.

False

7. Women using the Mirena ${ }^{\circledR}$ IUS will ovulate normally in the majority of cycles.

True

8. Ethinyloestradiol is more effective than placebo in reducing bleeding side effects with Norplant ${ }^{\circledR}$.

True

9. Oestrone is no better than placebo in reducing bleeding side effects with Depo-Provera ${ }^{\circledR}$.

True

10. The use of oestrogen with the POP may affect contraceptive protection.

True 